\title{
Wound vacuum-assisted closure as a bridge therapy in the treatment of infected cranial gunshot wound in a pediatric patient: illustrative case
}

\author{
Harjus Birk, MD, ${ }^{1}$ Audrey Demand, MD, ${ }^{1}$ Sandeep Kandregula, MBBS, ${ }^{1}$ Christina Notarianni, MD, ${ }^{1}$ Andrew Meram, DDS, MD, ${ }^{2}$ and \\ Jennifer Kosty, $\mathrm{MD}^{1}$
}

Departments of ${ }^{1}$ Neurosurgery and ${ }^{2}$ Oral and Maxillofacial Surgery, Louisiana State University Health Shreveport School of Medicine, Shreveport, Louisiana

BACKGROUND The authors reported the first pediatric case of a craniocerebral gunshot injury successfully treated with a wound vacuum-assisted closure (VAC) device after dehiscence and infection of the initial cranial wound.

OBSERVATIONS A 17-year-old boy suffered several gunshots to the left hemisphere, resulting in significant damage to the scalp, calvaria, and brain. Emergency hemicraniectomy was performed, with reconstruction of a complicated scalp wound performed at the initial surgery. The scalp was devitalized and ultimately dehisced, resulting in a cranial infection. It was treated first with a repeated attempt at primary closure, which failed because of persistent devitalized tissue, and was then treated with aggressive debridement followed by placement of a wound VAC device over the exposed brain as a bridge therapy to reconstruction. This procedure was deemed necessary given the active infection.

LESSONS The patient received delayed reconstruction with a free split-thickness skin graft and made a remarkable recovery, with cranioplasty performed 6 months later. The authors reviewed the literature on wound VAC use in cranial wound treatment and proposed it as a legitimate bridge therapy to definitive reconstruction in the setting of dirty wounds, active infection, or even hemodynamically unstable patients.

https://thejns.org/doi/abs/10.3171/CASE21489

KEYWORDS vacuum-assisted closure; cranial gunshot wound; pediatric; trauma; graft; bridge therapy

Craniocerebral gunshot injuries (CGls) present surgical challenges for neurosurgeons and carry a grim prognosis for patients, with reported survival rates of $7 \%-15 \%{ }^{1}$ For survivors, urgent surgical decompression may be necessary, but closure of the wound, which is often complex, may present a challenge. ${ }^{2}$

In this case report, we describe a 17-year-old patient who suffered a CGI to the left hemisphere, which resulted in significant injury to both the brain and scalp. After a complicated infection with multiple debridements, we were unable to primarily close the scalp and had to rely on placement of a wound vacuum-assisted closure (VAC) device over the injured brain to sterilize the site for a delayed free-flap. The patient did well with this intervention and has made a tremendous neurological recovery.

\section{Illustrative Case}

A 17-year-old boy presented to the emergency department after being found in a car with multiple gunshot wounds, including at least one involving the left hemisphere of the brain (Fig. 1). Upon examination, his scalp appeared macerated by fragments of bullet and bone, and brain matter was noted to be herniating through the defects. His Glasgow Coma Scale (GCS) score was 7T, and he was localizing with the left upper extremity. Initial imaging demonstrated a large left frontal, parietal, and temporal hematoma with $7 \mathrm{~mm}$ of midline shift and multiple intraparenchymal bullet and bone fragments. This was accompanied by a comminuted fracture of the left parietal bone with extension to the left frontal bone, left frontal sinus, and left orbital roof. Because of the mass effect of the hematoma, the patient received an emergency left-sided hemicraniectomy with partial clot evacuation, cranialization of the left frontal sinus, and repair of complex scalp lacerations.

A standard trauma flap procedure was performed, and the dura was opened in a stellate fashion. The left frontal sinus was cranialized and covered with a pericranial flap. A combination of continuous irrigation and gentle suction was used to evacuate as much of

ABBREVIATIONS CGI = craniocerebral gunshot injury; CSF = cerebrospinal fluid; $G C S=$ Glasgow Coma Scale; VAC $=$ vacuum-assisted closure INCLUDE WHEN CITING Published February 21, 2022; DOI: 10.3171/CASE21489.

SUBMITTED August 26, 2021. ACCEPTED December 16, 2021.

(c) 2022 The authors, CC BY-NC-ND 4.0 (http://creativecommons.org/licenses/by-nc-nd/4.0/). 


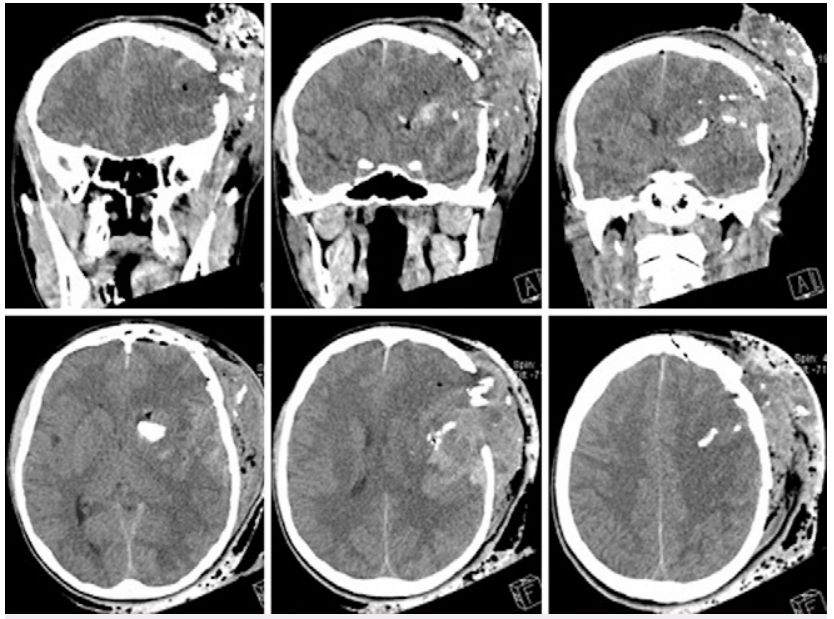

FIG. 1. Preoperative CT of the head demonstrating the extent of scalp, calvarial, and brain injury from several gunshots to the head.

the blood clot and bullet fragments as could be safely removed. A dural substitute was placed over the brain, and the dural edges were tucked over the top of this substitute circumferentially. A second substitute was laid over the top of this. To close the scalp with minimal tension, the plane between the galea and pericranium was mobilized to rotate additional scalp tissue toward the wound. Prior to closing the flap, the galea and remaining subcutaneous tissue from the macerated portion of the laceration were closed with 3-0 Vicryl. The flap was then closed with 2-0 Vicryl and staples, and stellate lacerations were closed with running 3-0 nylon sutures.

The patient had a complicated hospital course. The portion of his scalp flap that included the complicated lacerations appeared to suffer from inadequate blood flow, and on postoperative day 9 , the patient developed a fever and the wounds opened, expelling brain tissue (Fig. 2). Vancomycin and rocephin were started and the patient returned to the operating room, with oral and maxillofacial surgeons assisting with the reconstruction. A large portion of nonviable and infected brain tissue was removed. The edges of the necrotic laceration were excised to healthy skin, and the laceration as well as the flap were closed primarily. Intraoperative cultures were positive for Enterobacter cloacae. An external ventricular drain as well as a subdural and subgaleal drain were placed after the surgery in an attempt to divert CSF from the wound and facilitate skin edge closure.

Although the appropriate antibiotics were continued, the patient had continued leakage of CSF through his cranial incisions. He again returned to the operating room on postoperative day 15 , and aggressive margins of necrotic tissue along the scalp were excised.

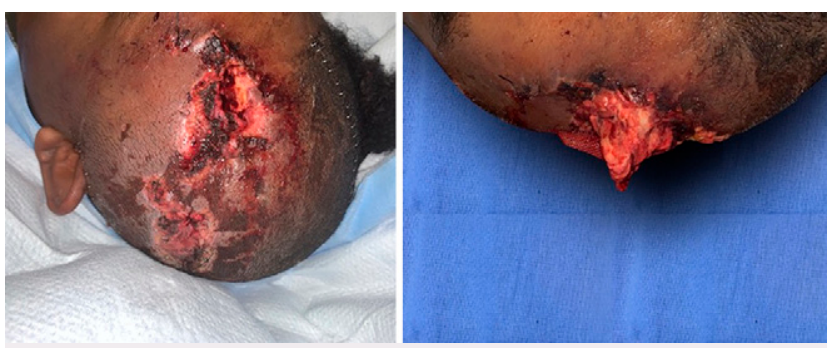

FIG. 2. The patient's scalp after the initial dehiscence.

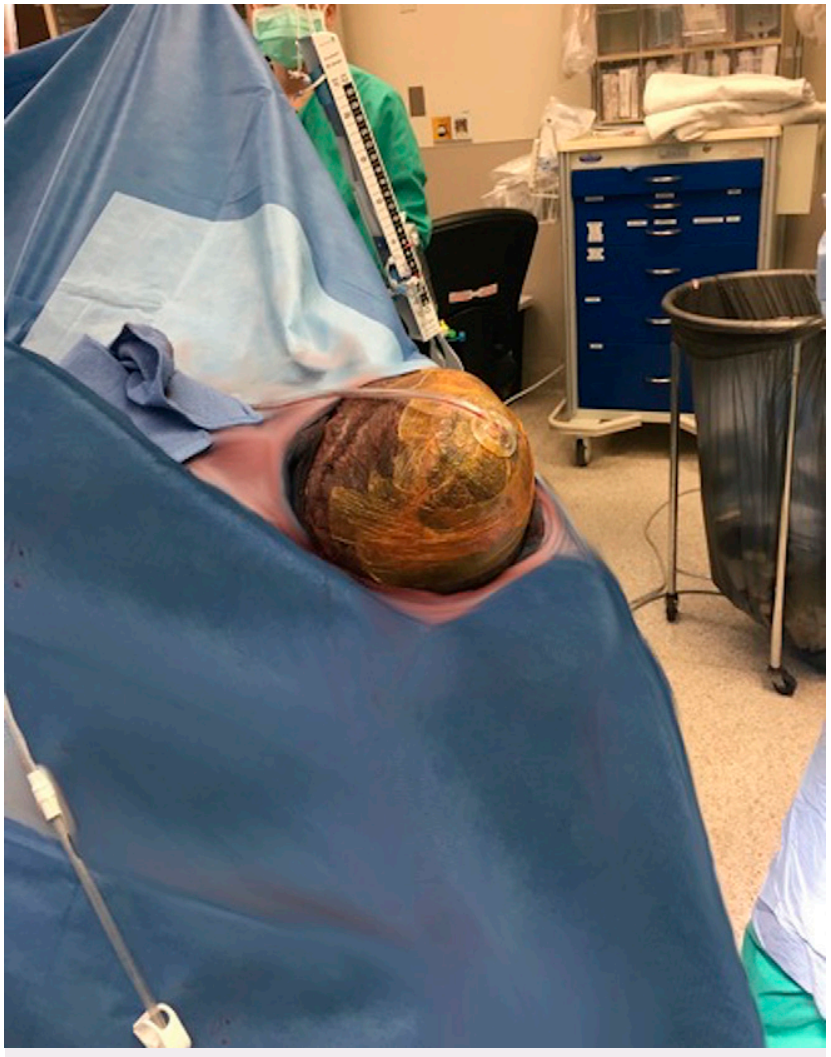

FIG. 3. Patient with the wound VAC placed over the exposed brain after extensive debridement.

Once they were primarily closed, there was a large portion of exposed brain tissue that could not be closed, and because there was an active infection, the decision was made to place a wound VAC for several weeks until the infection cleared (Fig. 3). loban was placed on the scalp along the perimeter of the defect. A wound VAC sponge was measured and cut to fit the wound bed size. loban was then used to cover the sponge, and the suction device was applied and hooked to the negative pressure device. The wound VAC was then set and confirmed to hold negative pressure suction continuously at $70 \mathrm{~mm} \mathrm{Hg}$. Two additional VAC changes were performed on postoperative days 18 and 21. After the second change, the VAC was set to $125 \mathrm{~mm} \mathrm{Hg}$ low-intensity negative pressure; after the third change, it was set to $100 \mathrm{~mm} \mathrm{Hg}$.

The wound VAC continued, and granulation tissue formation was confirmed in between VAC changes (Fig. 4). The patient returned to the operating room for a total scalp advancement rotational flap with a free split-thickness skin graft from the right thigh to scalp on postoperative day 24 . He was discharged to an inpatient rehabilitation facility for 2 weeks, at which time his GCS score was 11 . He returned to our clinic 6 months after his surgery. At that time, his tracheostomy had been decannulated and he was able to walk, speak, and understand commands. His cranial and thigh wounds had healed well, and cranioplasty was performed. Figure 5 demonstrates the VAC therapy mechanism with tissue layer depiction.

\section{Discussion}

To the best of our knowledge, this is the first reported cranial gunshot wound treated with a VAC device in a pediatric patient. Cranial 


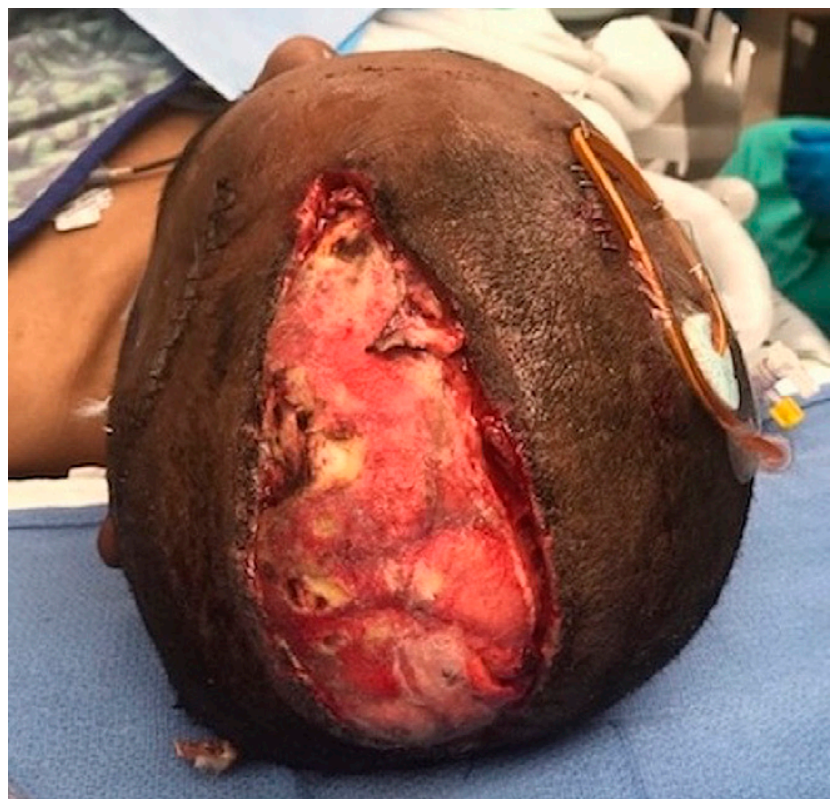

FIG. 4. Granulation tissue forming over the brain as seen after the first VAC exchange.

gunshots often result in complex wounds with nonviable tissue from high-velocity ballistic damage. The use of VAC therapy has been increasingly used for complicated nonneurosurgical wounds; however, it remains a novel treatment for complex cranial wounds, especially in the setting of CGls.

VAC therapy was pioneered by Western European surgeons in the 1990s for complex wounds involving the abdomen and extremities. ${ }^{3,4}$ In the United States, its use was first described in 1997 by Morykwas et al. as a means for creating negative pressure and removing edematous fluid and proteinaceous materials from wounds while enhancing blood supply and granulation tissue formation, allowing for improved wound formation and collagen deposition. 5,6 Through this vacuum mechanism, negative pressure values of 75 and $150 \mathrm{~mm} \mathrm{Hg}$ promote optimal wound healing by increasing collagen fibers and angiogenesis by elevating levels of vascular endothelial growth factor. ${ }^{7,8}$ Wound VAC therapy has gained considerable popularity and become a mainstay in treating many complex wounds, including diabetic ulcers, abdominal wounds, burn wounds, and skin grafting. VAC therapy has also been shown to be costeffective by reducing duration of hospital stay. ${ }^{9}$

With these numerous benefits, VAC therapy has been used widely for medical conditions ranging from abdominal defects to pressure sores and gynecological wound failures. Its use in neurosurgery for cranial wounds, however, is limited, with reports of only 12 such cases (Table 1). Ten of these cases were due to nontraumatic conditions such as invasive carcinomas and spontaneous hemorrhage. In only two cases was VAC therapy reported to be used in neurosurgical trauma.

There is only one other case in which a wound VAC was used in the setting of a CGI. This case was presented by Powers et al. and involved a 24-year-old man who sustained a gunshot wound to
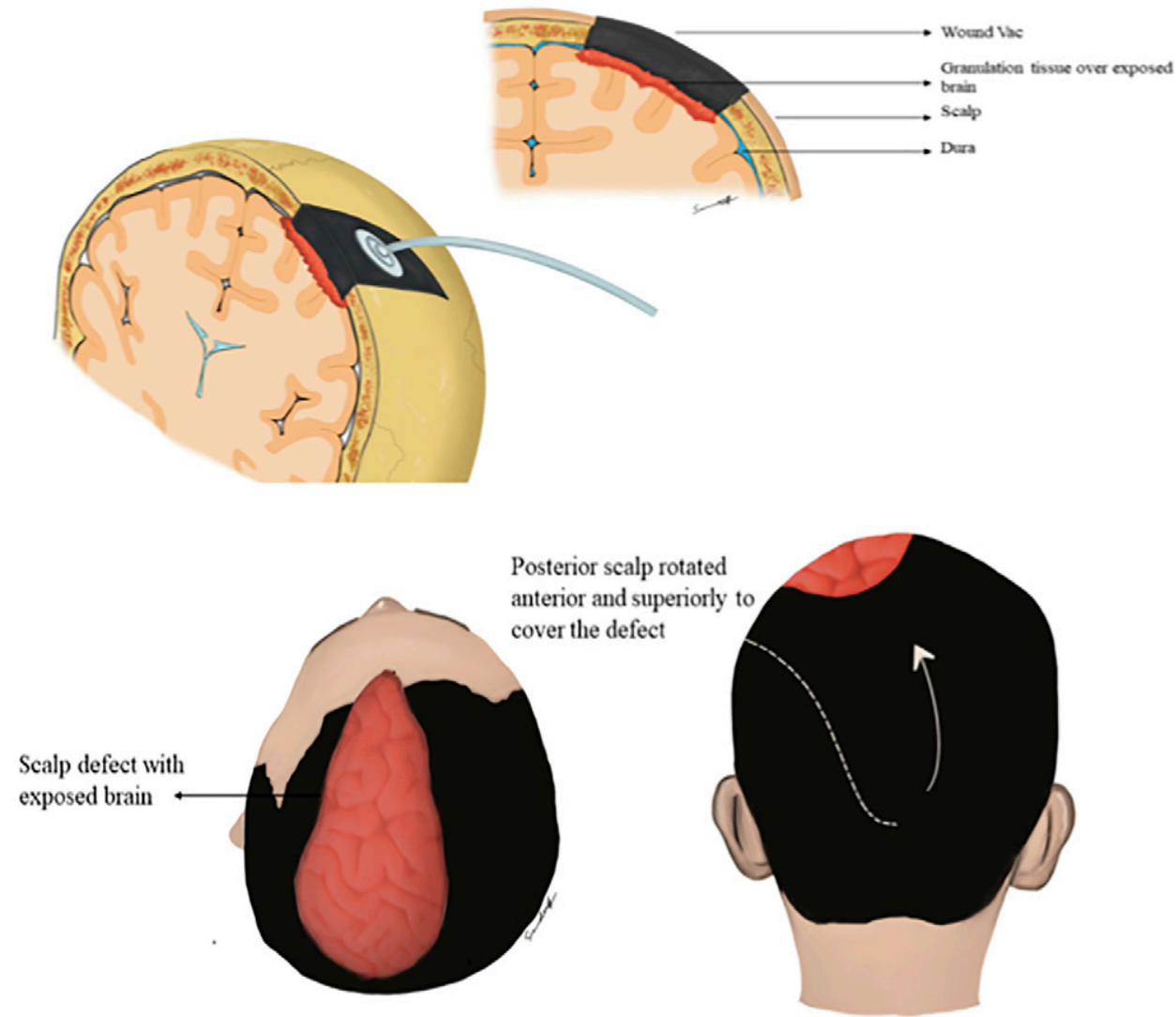

FIG. 5. VAC therapy mechanism with tissue layer depiction. 
TABLE 1. Review of the literature of VAC therapy for complex cranial wounds

\begin{tabular}{|c|c|c|c|c|c|c|}
\hline Authors \& Year & $\begin{array}{l}\text { Age/ } \\
\text { Sex }\end{array}$ & Patient History & $\begin{array}{l}\text { Reason VAC } \\
\text { Pursued }\end{array}$ & $\begin{array}{l}\text { Duration of } \\
\text { VAC (days) }\end{array}$ & Definitive Treatment & Outcome \\
\hline \multirow[t]{4}{*}{ Powers et al., $2013^{5}$} & $69 / M$ & $\begin{array}{l}\text { Invasive scalp squamous cell } \\
\text { carcinoma }\end{array}$ & Infection & 91 & Latissimus free flap & $\begin{array}{l}\text { Death due to } \\
\text { respiratory failure }\end{array}$ \\
\hline & $73 / \mathrm{M}$ & Subdural empyema & Infection & 30 & $\begin{array}{l}\text { Family transitioned to } \\
\text { comfort care }\end{array}$ & $\begin{array}{l}\text { Death due to } \\
\text { respiratory failure }\end{array}$ \\
\hline & $75 / F$ & Invasive atypical meningioma & Infection & 71 & STSG & Good wound healing \\
\hline & $24 / M$ & Cranial gunshot wound & Infection & 32 & $\begin{array}{l}\text { Delayed primary } \\
\text { closure }\end{array}$ & Good wound healing \\
\hline \multirow[t]{3}{*}{ Prince et al., $2015^{6}$} & $66 / M$ & $\begin{array}{l}\text { Invasive scalp squamous cell } \\
\text { carcinoma }\end{array}$ & Infection & 6 & Autologous graft & $\begin{array}{c}\text { Subcentimeter wound } \\
\text { breakdown that } \\
\text { eventually healed }\end{array}$ \\
\hline & $75 / F$ & Basal cell carcinoma & Infection & 5 & STSG & Good wound healing \\
\hline & $56 / F$ & Ruptured aneurysm & Infection & 7 & $\begin{array}{l}\text { Free radial forearm } \\
\text { flap }\end{array}$ & Good wound healing \\
\hline Ahmed et al., $2015^{10}$ & $68 / F$ & $\begin{array}{c}\text { Traumatic SDH complicated } \\
\text { by empyema }\end{array}$ & Infection & 15 & Thigh free flap & Good wound healing \\
\hline Makler et al., $2018^{11}$ & $56 / F$ & $\begin{array}{l}\text { Invasive scalp squamous cell } \\
\text { carcinoma }\end{array}$ & Infection & 30 & $\begin{array}{l}\text { None; death due to } \\
\text { carcinoma }\end{array}$ & $\begin{array}{l}\text { Death due to } \\
\text { carcinoma }\end{array}$ \\
\hline
\end{tabular}

SDH = subdural hematoma; STSG = split-thickness skin graft.

the face that extended into the anterior fossa. ${ }^{5}$ He received emergency surgery, and in addition to facial wound debridement, foreign material was maximally removed from the brain. However, the scalp and dura were macerated. A pericranial flap was used to close the dural laceration, but direct primary closure of the scalp was delayed because of concern of infection from the foreign bodies. As such, a wound VAC was placed and maintained for 32 days, and an eventual delayed primary closure was successfully performed. The patient was neurologically stable throughout treatment with the VAC device.

VAC therapy has also been used in the setting of neurosurgical trauma for a wound infection after craniotomy. In that case, a 68-yearold woman who suffered a traumatic fall received emergency left-sided craniotomy and evacuation of a subdural hematoma. ${ }^{10}$ She had a fast recovery and was discharged on postoperative day 7 . However, on postoperative day 19, she became febrile and the wound dehisced. Cultures grew Staphylococcus aureus and antibiotics were initiated. The wound continued to dehisce, and the bone flap was removed. The dura and scalp showed necrosis, and a wound VAC was then placed after resecting the necrotic scalp. In 1 week, granulation tissue was evident upon wound VAC changes. Once the treatment course for the infection was completed, the patient received anterolateral thigh free flap surgery. At 6-month follow-up, the flap was healing, and the patient was neurologically well.

\section{Observations}

With cranial gunshot wounds, small scalp defects may be treated with primary closure whereas larger defects can be treated with free or rotational flaps. ${ }^{11,12}$ However, the difficulty of a flap reconstruction, paired with a patient history of infection or concern for a dirty wound, makes these complex cranial wound closures even more challenging. VAC therapy is emerging as an interesting bridge to delayed grafting.

The potential benefits of VAC therapy in cranial wound management are evident when reviewing complex cranial wound closures that were managed upfront with reconstruction. Krishnan et al. presented 49 neurosurgical patients who received complex wound closure directly after initial diagnosis and pathology, which ranged from trauma to invasive brain tumors. Free flaps and rotational flaps were performed as closure techniques, and healing was not optimal in patients who had infection or CSF leaks, often resulting in wound breakdown. ${ }^{13}$ Limitations of VAC therapy in cranial wound treatment include the need for frequent wound VAC changes to aid growth of granulation tissue, skin irritation, and risk of bleeding by way of negative pressure, particularly in patients on anticoagulants.

The biggest risk factor for inadequate cranial wound closure is previous failed attempts secondary to scar tissue and impaired vascularity at the revised wound sites. ${ }^{10-13}$ VAC therapy indications include such cases in which the patient needs time (e.g., to resolve an infection, before autologous grafting, or because of complicated reconstruction). It might also be useful in the setting of an unstable patient. Prince et al. analyzed the efficacy of VAC therapy, specifically in patients with infected complex cranial wounds. Because of these infections, going directly to a free flap, rotational flap, or other closure technique would not be prudent. Of five patients studied, all 
experienced success with VAC therapy as a temporizing measure that increased the likelihood of eventual graft success. These VAC devices were used for a total of 3 to 7 days in this patient group. Once the infections were resolved in these patients, they received successful free flaps or rotational advancement flaps. ${ }^{6}$ In our case, because the patient had an effective aggressive initial surgery to remove the hemorrhage and bullet fragments, primary closure was performed instead of using VAC therapy directly. VAC therapy was performed as a last resort after persistent infection and extreme wound dehiscence.

In summary, the advantages of using VAC therapy to cover the brain in instances of devitalized scalp injury are multifold. First, in cases of gunshot trauma in which there is increased risk of infection due to foreign bodies, VAC therapy allows for protection of the brain by providing a safe wound environment under gentle negative pressure. Second, VAC therapy can help bridge the gap between immediate wound repair and long-term wound healing, allowing time for the neurosurgeon to plan for ideal reconstruction. Lastly, in cases in which the graft may ultimately fail, VAC therapy for cranial wounds can be used as a stand-alone wound closure therapy. A disadvantage of using VAC therapy for complex cranial wounds is the possibility of CSF overdrainage. It is critical to minimize CSF space by performing primary dural closure when feasible. This may not be possible in cases involving trauma, infection, and tumor in which the dura is not fully intact. In these cases, one may consider use of synthetic dural matrix or an autologous graft. However, in our case, no synthetic dural matrix or autologous graft was used, and the patient was managed safely with frequent neurological checks and careful attention to the volume of aspirate in the VAC device.

\section{Lessons}

We present, to the best of our knowledge, the first pediatric patient with an extensive cranial wound secondary to a CGI in whom VAC therapy was used with successful outcomes. In this young patient, VAC therapy served as a bridge therapy in the setting of an infected wound bed, allowing for delayed repair with a split-thickness skin graft. Although initial primary closure of these complex wounds may be desirable, in situations in which there is concern for a dirty wound, a known infection, or even hemodynamic instability with a significant scalp defect, wound VAC placement may be an excellent bridging therapy to definitive scalp reconstruction.

\section{References}

1. Tsuei YS, Sun MH, Lee HD, et al. Civilian gunshot wounds to the brain. J Chin Med Assoc. 2005;68(3):126-130.

2. Alvis-Miranda HR, Adie Villafañe R, Rojas A, Alcala-Cerra G, Moscote-Salazar LR. Management of craniocerebral gunshot injuries: a review. Korean J Neurotrauma. 2015;11(2):35-43.

3. Kim TW, Lee JK, Moon KS, et al. Penetrating gunshot injuries to the brain. J Trauma. 2007;62(6):1446-1451.

4. Morykwas MJ, Argenta LC, Shelton-Brown El, McGuirt W. Vacuumassisted closure: a new method for wound control and treatment: animal studies and basic foundation. Ann Plast Surg. 1997; 38(6):553-562.

5. Powers AK, Neal MT, Argenta LC, Wilson JA, DeFranzo AJ, Tatter $\mathrm{SB}$. Vacuum-assisted closure for complex cranial wounds involving the loss of dura mater. J Neurosurg. 2013;118(2):302-308.

6. Prince N, Blackburn S, Murad G, et al. Vacuum-assisted closure therapy to the brain: a safe method for wound temporization in composite scalp and calvarial defects. Ann Plast Surg. 2015; 74(4 suppl):S218-S221.

7. Kim JJ, Franczyk M, Gottlieb LJ, Song DH. Cost effective alternative for negative-pressure wound therapy. Plast Reconstr Surg Glob Open. 2017;5(2):e1211.

8. Zhou M, Yu A, Wu G, Xia C, Hu X, Qi B. Role of different negative pressure values in the process of infected wounds treated by vacuum-assisted closure: an experimental study. Int Wound J. 2013;10(5):508-515.

9. Vuerstaek JD, Vainas T, Wuite J, Nelemans P, Neumann MH, Veraart JC. State-of-the-art treatment of chronic leg ulcers: a randomized controlled trial comparing vacuum-assisted closure (V.A.C.) with modern wound dressings. J Vasc Surg. 2006;44(5):1029-1037, discussion 1038.

10. Ahmed O, Storey CM, Zhang S, Chelly MR, Yeoh MS, Nanda A. Vacuum-assisted closure of necrotic and infected cranial wound with loss of dura mater: a technical note. Surg Neurol Int. 2015;6:11.

11. Makler V, Litt JS, Litofsky NS. Palliative coverage of cranial defect following failed cranial flap for advanced squamous cell carcinoma: case report. J Palliat Med. 2018;21(1):109-113.

12. Suddaby $L$, Weir $B$, Forsyth $C$. The management of .22 caliber gunshot wounds of the brain: a review of 49 cases. Can J Neurol Sci. 1987;14(3):268-272.

13. Krishnan KG, Müller A, Hong B, et al. Complex wound-healing problems in neurosurgical patients: risk factors, grading and treatment strategy. Acta Neurochir (Wien). 2012;154(3):541-554.

\section{Disclosures}

The authors report no conflict of interest concerning the materials or methods used in this study or the findings specified in this paper.

\section{Author Contributions}

Conception and design: Birk, Demand, Meram, Kosty. Acquisition of data: Demand, Meram. Analysis and interpretation of data: Birk, Demand. Drafting the article: Birk, Demand, Kandregula, Meram, Kosty. Critically revising the article: Birk, Notarianni, Meram, Kosty. Reviewed submitted version of manuscript: Birk, Notarianni, Meram, Kosty. Approved the final version of the manuscript on behalf of all authors: Birk. Administrative/technical/material support: Notarianni, Kosty. Study supervision: Notarianni, Kosty.

\section{Correspondence}

Harjus Birk: Louisiana State University Health Shreveport, Shreveport, Shreveport, LA. harjus.birk@Isuhs.edu. 